\title{
DISCURSO DE POSSE DE DIRETOR DA FACULDADE DE DIREITO DA UNIVERSIDADE DE SÃO PAULO - 2018-2022
}

\author{
INAUGURAL SPEECH OF THE DEAN OF THE UNIVERSITY OF SÃO PAULO \\ LAW SCHOOL - 2018-2022
}

Floriano Peixoto de Azevedo Marques Neto*

- Magnífico Reitor, Professor Vahan Agopyan.

- Meu amigo dileto José Rogério Tucci, a quem tenho a honra de suceder.

- Meu caro Vice-Diretor ora empossado Professor Celso Fernandes Campilongo.

- Professora Titular Sênior Odete Medauar em nome de quem saúdo todos os professores aqui presentes.

- Ministros Lewandowski, Alexandre de Moraes, Dias Toffoli e Eros Grau.

- Amigos, colegas da turma de 90.

- D. Luiza, minha mãe, em nome de quem saúdo meus familiares e do Professor Celso.

- Autoridades presentes.

1. Introdução

Refletindo sobre as palavras que traria a essa solenidade, concluí que uma solenidade de posse é uma festividade com vários significados.

Ao mesmo tempo em que se renova a confiança e a expectativa nos que tomam posse, somos lembrados da responsabilidade e dos desafios que se apresentam nos anos vindouros.

Tentação irresistível, lembrei-me do célebre discurso de Churchill perante o parlamento inglês ao assumir em plena guerra o cargo de primeiro-ministro. Não estamos em guerra. Nem cometeria a indelicadeza de oferecer aqui apenas sangue, suor e trabalho.

Mas não posso me limitar a apenas celebrar. É dever do empossado agradecer, mas também celebrar e reiterar seus compromissos e desafios.

A posse é sempre um momento de festa, mas é também oportunidade para balanço e para projetarmos o porvir.

* Professor Titular do Departamento de Direito do Estado da Faculdade de Direito da Universidade de São
Paulo. 
2. Balanço pessoal

Começo por um balanço pessoal.

Sou franciscano desde antes de me tornar aluno.

$\mathrm{Na}$ entrevista de aplicação no colégio em que cursaria o que hoje chamamos de ensino médio, àquele tempo o colegial, respondi de modo peremptório à inevitável pergunta sobre o que pretendia fazer na continuidade de minha formação: Quero fazer Direito no Largo de São Francisco.

Aqui estou, quase ininterruptamente, há 32 anos, mais de três quintos de minha vida.

Nada mais gratificante que poder dedicar meu próximo quadriênio à Faculdade, para ajudar nossa escola a ser mais forte, aberta e moderna.

Fácil entender o significado para mim deste momento, porém longe de ser este um momento de consagração, trata-se de um novo início. Início de um novo ciclo pessoal, mas também a oportunidade de iniciar um novo ciclo dessa academia. Ciclo que se baseia na convicção de que é hora de doar um pouco mais à instituição que - generosa - tanto me ofereceu.

Assumo o desafio de dirigir esta quase bicentenária escola num momento particularmente feliz para mim.

Meus mais de trinta anos de São Francisco, metade dos quais como professor, me permitem conhecer a Faculdade, seu potencial, falhas e limites.

Ao mesmo tempo me sinto jovem e portador da energia e da disposição para o grande trabalho a ser feito.

Não é pouco o que temos por fazer, mas estou disposto a fazer o que tem que ser feito.

3. Condições objetivas nunca tão favoráveis

As condições objetivas não poderiam ser melhores.

3.a. Legado Tucci

Recebo a Faculdade em condições raras.

A gestão de meu antecessor, professor e amigo José Rogério Tucci, além de avanços esperados por décadas - como a reforma da graduação, as políticas de inclusão, melhorias nas instalações - permitiu que recebêssemos um ambiente pacificado, de diálogo franco, fidalgo e fraterno, algo tão escasso no mundo contemporâneo.

A gestão que ora se encerra honra esta Faculdade e, apesar de colocar o crivo de comparação bem elevado, facilita muito a vida dos seus sucessores. 


\section{3.b. Professor Celso Campilongo}

Tenho a fortuna de ter como meu Vice-Diretor o Professor Celso Campilongo. Amigo a quem devo o início da minha carreira docente.

Comecei como seu assistente aqui e na PUC-SP. Além de um grande amigo, um professor invejável, testado no serviço público como Conselheiro do CADE e Secretário Executivo do MJ.

Mais que seus conhecidos predicados, Celso é homem de dignidade e humildade ímpares. Resistiu a aceitar meu convite para integrar a chapa. Dizia não se achar o melhor nome. Aceitou quando, algo raríssimo, recebeu manifestação unânime de todos os chefes dos nove departamentos apoiando sua candidatura a vice. Celso, estejam certos, definitivamente não será um "vice decorativo", da memória histórica recente. Será meu consorte e companheiro na gestão e na condução de nossa academia nos próximos anos.

\section{3.c. Professor Vahan Agopyan}

Tenho também a sorte de assumir quase concomitantemente ao início do mandato do Magnífico Reitor. Conheço o Professor Vahan Agopyan desde sua presidência no IPT, sei de sua dedicação e de sua visão de Universidade, com a qual compartilho. Estou certo que, apesar das sabidas dificuldades financeiras da USP poderemos contar com o firme apoio dos órgãos centrais da Universidade.

\section{3.d. O momento histórico}

Mas o que mais me inspira é que assumimos a Diretoria de uma Faculdade em franca renovação. A renovação do quadro docente havida nos últimos dez anos é invulgar. A disposição dos meus pares para enfrentar os problemas e empreender as mudanças necessárias me surpreende e entusiasma. Ao longo da campanha e depois da eleição recebi não apenas cumprimentos e apoios formais, mas inequívocas manifestações de apoio e disposição de colaborar, de assumir responsabilidades. O quadro de servidores, desfalcado pelas inevitáveis reduções de pessoal ditadas pela crise financeira, dá mostras diárias de dedicação e superação. E os alunos, como sói há quase duzentos anos, são a força vital que não nos permite estagnar, mais ainda agora que à contumaz excelência se soma a diversidade. E só o fato de termos recebido mais de $80 \%$ dos votos é prova da conjuntura única e da confiança que nos foi depositada. 
4. Os desafios

As condições objetivas e subjetivas são ideais. Mas os desafios, estou ciente, são proporcionais.

Não é singela a tarefa de dirigir uma instituição com quase dois séculos de história, que foi dirigida por tantos e tão importantes acadêmicos, com tanta história e tradição. A missão se mostra ainda mais desafiadora diante do que está por ser feito. E temos pressa, pois como disse certa feita Max Weber "o desperdício de tempo é o principal de todos os pecados". Não podemos mais desperdiçar tempo com problemas já de há muito diagnosticados. A São Francisco é parte de uma Universidade Pública e como tal deve ser encarada. Mesmo que tivéssemos maior disponibilidade de recursos públicos, nunca seria possível que a Universidade Pública ofereça educação superior de qualidade a todos os egressos do ensino médio. Sempre haverá uma seleção, mais ou menos inclusiva. Isso demarca dois compromissos inarredáveis para a USP.

Primeiro compromisso: a amplitude de sua função.

Não basta oferecer bom ensino e preparar bons quadros profissionais. Isso é o mínimo. A função da Universidade Pública é produzir e difundir conhecimento de ponta, formar quadros aptos a liderar os diversos segmentos do conhecimento, da sociedade civil e do Estado. Uma Faculdade de Direito de uma Universidade Pública, dá a seus alunos a oportunidade de serem grandes advogados, brilhantes juízes, promotores, defensores públicos, mas se só isso fizer, estará usando recursos escassos para formar poucos e bons. Temos que ir além - e com orgulho posso dizer que temos ido. A estas arcadas não basta formar bons operadores da lei é preciso formar quadros críticos para transformar e inovar as leis, como no passado fizemos com o Código Civil de Reale, a Lei da Ação Civil Pública de Ada Grinover e outros, a Lei de Arbitragem de Carmona e outros, o novo CPC de contribuição de vários de nossos colegas processualistas, a Lei de Processo Administrativo de Odete Medauar e Maria Sylvia, a Constituição de Ulysses Guimarães.

Cumpre à faculdade formar líderes do mundo político, cultural, social, sindical e empresarial. Não mais apenas líderes para a oligarquia ou as elites, mas líderes formados na pluralidade e na diversidade, para pontear em todos os matizes do espectro político e ideológico. Mais do que nunca, num momento de profunda crise política, institucional e econômica, cabe à Faculdade de Direito da USP cumprir sua função de oferecer ao país propostas, quadros, alternativas.

O segundo compromisso é o inarredável senso de dever.

Fazer parte de uma Universidade Pública nos obriga a um profundo senso de dever. Não basta ao corpo docente oferecer boas aulas de graduação e pós, orientar pesquisas, coordenar atividades de extensão, dar cabo burocraticamente de nossas atribuições. Temos que nos dedicar mais a cada dia para empolgar os alunos, para 
fomentar o debate sério e respeitoso, para despertar a reflexão e a crítica. Não basta aos servidores cumprirem sua jornada de trabalho e darem conta de suas atribuições. É preciso se desdobrar, gostar do que fazemos, buscar ser mais eficientes, sugerir melhorias.

Aos alunos de uma escola pública estudar para passar de período é pouco. É preciso ter a noção do que representa a oportunidade que a sociedade lhes franqueia, e se propor a explorar os limites da crítica, pesquisar, questionar, ir além. Numa Universidade Pública, já disse, somos todos servidores e devemos nos orgulhar de servir à sociedade que nos destina escassos e preciosos recursos. É com essa clara missão de dirigir uma Faculdade de Direito de uma Universidade Pública, da melhor delas, que assumo sua direção nesta noite. Não apenas com a missão de mantê-la como a melhor, mas com a missão de fazê-la a cada dia melhor.

\section{Seis eixos de atuação}

Dar cabo dessa missão a meu ver envolve atuar em seis eixos, a s a b e r : diversidade, atualidade, criatividade, relevância, transparência e excelência.

\section{5.a. Diversidade}

Ainda que com atraso no ensino superior, fomos pioneiros na USP na introdução do processo de seleção com reserva de vagas aos egressos de escolas públicas. O ganho com a mudança de perfil dos nossos alunos já vem sendo sentido. A diversidade é uma riqueza. Com a ampliação desta política, doravante por regulamentação aplicável a toda a USP, a diversidade entre nossos alunos aumentará nos próximos anos, agora não mais apenas pelo viés social, mas também racial. Em 2021 teremos metade dos ingressantes vindos de escola pública, e destes, 37\% destinados aos declaradamente pretos, pardos e indígenas. Engana-se quem vê nessas políticas riscos ao nível de excelência de nosso alunado. Os processos seletivos, seja pela Fuvest, seja pelo Sisu são altamente rigorosos. Selecionamos os melhores. Nossa experiência nestes dois anos com os recrutados nas vagas destinadas aos estudantes de escolas públicas tem mostrado o acerto destas políticas: temos recebido alunos com grande capacidade de aprender e com enorme disposição. E o ganho com a diversidade de origens sociais, regionais e culturais não tem preço. Isso nos coloca um enorme desafio. Não basta apenas permitir o acesso, temos que dar condições de permanência para estes alunos; bolsas de estudo, condições de moradia e alimentação, apoio para os que vêm de outras cidades e outros estados. Mais que isso, temos que nos apetrechar para aproveitar ao máximo a riqueza das diferentes pertenças que aportam e aportarão em nossas arcadas. Um desafio enorme, mas igualmente empolgante. A diversidade também impõe o aprendizado da pluralidade. Aprender a ouvir quem pensa diferente, dialogar fora da eugenia de opiniões. Eis um desafio permanente, mas que se 
realça quando lidamos com gerações que costumam se comunicar no ambiente por vezes sectário das redes sociais. Manter aqui um ambiente em que o debate aberto e leal valha mais do que os likes ou os haters.

O pátio das Arcadas, a Sala dos Estudantes, o Porão do XI de Agosto, as Salas de Aula seguirão sendo mais abertas e democráticas que qualquer rede social. Nestes espaços não se exclui ninguém, neles não perduram as fake news, aqui não há nem pode haver discurso de ódio. Cumpre a todos nós manter um ambiente de diversidade de opiniões, credos, ideologias, confissões, opções; o respeito a quem é, age ou pensa diferente. A diversidade que sempre nos caracterizou, agora reforçada pela diferença de origens, é o nosso maior patrimônio. E seguirá sendo.

\section{5.b. Atualidade}

Não basta celebrar nossas tradições e nelas pararmos. Se somos o que somos, isso se deve ao fato de termos sempre sabido nos reinventar. A ruptura é da nossa tradição. O grande desafio aqui é o de saber nos atualizar, sem descurar de nossos alicerces. Essa tensão se apresenta em nossas instalações físicas. Este prédio é patrimônio histórico, como tal, tombado. É dever preservá-lo, mas isso não significa estarmos condenados a conviver com salas de concepção ultrapassada, mobília quebrada, recursos tecnológicos obsoletos. Recuperar salas e mobiliário, requalificar instalações, incrementar nossos recursos de informática, isso tudo é urgente. Mesmo sabedores da inexistência de recursos nos orçamentos da Universidade, é obrigação de todos, professores, servidores, alunos e ex-alunos somar esforços para encontrar alternativas de financiamento que ajudem a superar o impasse dentro dos cânones da Universidade Pública.

História e memória não são opostas à modernidade. Exemplo disso é a nossa biblioteca. Não é mais possível adiar a solução para acolher o nosso rico acervo de pesquisas, hoje tristemente espalhado em instalações improvisadas. O acervo da FD é também patrimônio público. Equacionar este problema é tarefa nossa, mas não apenas nossa. Outros atores, dentro e fora da Universidade, serão convocados a nos ajudar e resolver este problema tristemente já antigo. Mas a atualidade não se resume a instalações tinindo de novas. A cada ano recebemos gerações de jovens alunos alfabetizados no mundo digital, com características cognitivas muito distintas das gerações formadas nos anos 70, 80 ou 90. Não será possível seguir ensinando estes jovens com conteúdos do século XX e métodos do século XIX. É nosso dever revisitar conteúdos, disciplinas e projetos didáticos. Sem isso viveremos em breve um apagão de aprendizagem grave e sem precedentes. 
5.c. Criatividade

Disse a pouco que estamos cientes da responsabilidade de enfrentar metas ambiciosas em cenário de escassez. Impõe sermos criativos e buscar alternativas. Alternativas de gestão. Alternativas de financiamento. A gestão administrativa e acadêmica da FD tem de ser repensada. É preciso aumentar a comunicação e a articulação entre as comissões permanentes. Otimizar a alocação dos nossos valorosos mas escassos recursos humanos. Igualmente temos que apoiar e divulgar nossos esforços de internacionalização. Investir mais no intercâmbio com instituições respeitáveis de fora do país e mesmo nacionais. Quebrar nossos muros só nos fará melhores. Temos que aprender a gerenciar melhor nossos recursos, que são cada vez mais escassos. Temos que enfrentar francamente o debate sobre o concurso de recursos da sociedade para custear nossos projetos. Obter recursos, públicos ou privados, sempre desafia nossa autonomia. Não aceitaremos abrir mão de nossa autonomia de ensino e pesquisa para obter recursos seja do orçamento público, seja de contribuições privadas. Contudo, estou certo que podemos contar com o apoio de várias fontes sem abrir mão de nossas premissas. A cada ano a Faculdade forma mais de quatro centenas de bacharéis. Todos zelosos e devedores do que aqui receberam. A contribuição destes colegas, mesmo que modesta, pode fazer grande diferença em bolsas de permanência ou melhorias pontuais de infraestrutura. Muitos profissionais hoje bemsucedidos foram acolhidos na casa do estudante durante seus anos de graduação. Diante de um projeto sério e viável não se negarão a contribuir para melhoria da moradia estudantil. A Faculdade de Direito do Largo de São Francisco é uma instituição paulista e nacional. Instituições públicas e privadas podem muito bem se associar a projetos interessantes e bem formatados, contribuindo pela melhoria de nossas condições de ensino e pesquisa.

\section{5.d. Relevância e inserção na sociedade e no debate nacional}

O país passa por um momento bastante crítico. Vivemos várias crises: econômica, fiscal, política, institucional. Estamos a passar por um permanente desafio aos direitos. Como já dizia Gofredo na Carta aos Brasileiros "a consciência jurídica exige uma coisa só: o estado de direito já". E acrescento: exige sempre, segue exigindo. Estado de Direito que não pode aceitar a corrupção e os desmandos, a permanência do patrimonialismo em todas as suas feições, mas que também não admite atalhos para a punição estatal, não se coaduna com gambiarras para combater a chamada impunidade. Estado de Direito que não comporta a tolerância com a escravidão, mácula odiosa, mas infelizmente ainda hodierna. Pelejar pelo Estado de Direito é também missão dessa academia e, para isso, impõe ocupar um lugar mais central no debate nacional. A Faculdade de Direito precisa ocupar posição de relevância neste momento. Quadros não 
lhe faltam, história tampouco. Suas credenciais são inegáveis. Temos o desafio de trazer de volta à nossa academia a discussão dos grandes temas nacionais. Já a partir deste ano, quando teremos importantes eleições, devemos não apenas discutir os nomes e projetos dos candidatos; cumpre a nós debater e oferecer soluções para diversas questões que nos desafiam. No momento em que nossa constituição completará 30 anos, é também nosso dever assumir um papel de relevância e destaque, debatendo a agenda constitucional, discutindo as reformas necessárias.

\section{5.e. Transparência}

Mais do que tudo, temos que ter transparência interna e externa. Não apenas a transparência orçamentária e administrativa, essa já imposta por lei. Internamente é nosso compromisso cultivar o debate transparente e responsável com todos os segmentos da comunidade. Um debate lhano e honesto, em que as partes exponham com transparência seus pontos de vista e concorram para superar impasses e divergências. É também dever aprimorar processos e normas, consolidando-as e tornando-as mais claras e objetivas. A começar, desde já, com a reforma do regimento interno da FD. Mas temos que melhorar a transparência de nossa comunicação com a sociedade. A começar com o aperfeiçoamento das ferramentas de comunicação com as redes sociais, trabalho já iniciado pelo professor Tucci com a reformulação do site da FD, com nova arquitetura, resta à nova gestão tornar possível a permanente atualização das informações. Igualmente é nosso compromisso melhorar a comunicação pelas redes com a comunidade interna e externa a São Francisco. Mais além, temos que nos comunicar melhor com a sociedade. De um lado, saber divulgar os resultados de nossas pesquisas e o importante trabalho desenvolvido nas dezenas de atividades de extensão por nossos professores e alunos. E de outro lado é nosso dever nos reaproximar dos meios de comunicação, especialmente a mídia impressa, oferecendo nosso conhecimento e apoio nas discussões atuais e no debate judiciário que ganha crescente importância.

\section{5.f Excelência}

Todos estes vetores convergem para o último e talvez o mais importante: temos o compromisso com a excelência. Devemos continuar obcecados por oferecer o melhor ensino, as melhores e mais sérias pesquisas, as atividades de extensão que façam a diferença para o público alvo. Não podemos nunca nos acomodar com apenas fazer bem nossas tarefas. Temos que ir mais além. Bom exemplo é o nosso programa de Pós-Graduação; temos o maior programa de mestrado e doutorado do Brasil. Somos responsáveis por formar mais da metade dos doutores em Direito existentes no país. Temos um quadro docente composto por quase duas centenas de doutores. Mais de 1.500 
alunos. Mas isso não pode obliterar a necessidade de repensá-lo, melhorá-lo, aperfeiçoálo. E assim faremos. A excelência só é possível se todos e cada um de nós mantiver acesa a inquietude, o inconformismo com o bom, a permanente pulsão por fazer mais e melhor. Quando olho meus colegas no doutoral, quando vejo os amigos e estudantes aqui presentes, tenho a certeza que esta academia é definitivamente vocacionada para a excelência.

Quando ainda candidato, um amigo de fora da Universidade me indagou? Afinal, o que faz o Diretor da Faculdade? Pergunta simples, quase protocolar. Refletindo sobre tal pergunta quando me preparava para esta solenidade, creio ter encontrado a resposta: antes de qualquer coisa cabe ao Diretor engajar e empolgar a comunidade acadêmica, não dirigi-la, mas direcioná-la para que todos empurrem nossa academia para seu crescimento e aperfeiçoamento. É a isso que nos propomos: trabalhar coletivamente para fazer estas arcadas melhores e mais unidas quando chegar em breve o tempo do seu bicentenário. Que venham então os desafios. Tucci, fique tranquilo, todos juntos faremos mais e melhor a partir do ponto em que você nos passa o bastão. De nossa parte, minha e de Celso, não faltará vontade, energia e disposição para a tarefa. Que venham os desafios! Afinal, o Franciscano só deixa a folha dobrada quando se vai morrer.

São Paulo, 12 de março de 2018. 


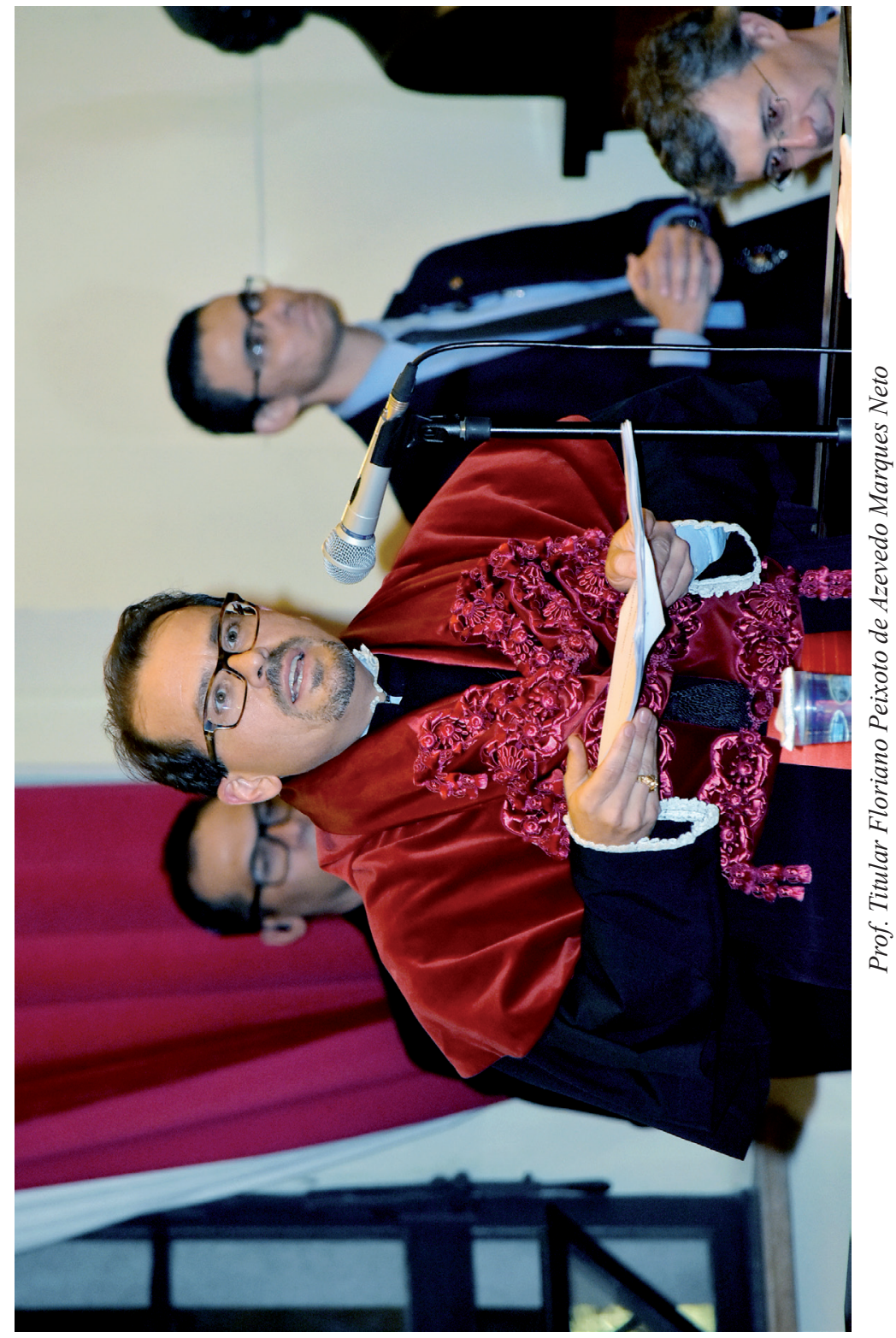

